\title{
AS ATRIBUIÇÕES DA EDUCAÇÃO FÍSICA ESCOLAR: um enfoque especial no Ensino Médio
}

Vanessa Gomes de Castro'

\section{RESUMO}

Trata-se de uma breve reflexão sobre as atribuições da Educação Física escolar ao longo do século XX e início do século XXI, com enfoque especial no ensino médio. O objetivo principal é pontuar de forma crítica, com base em documentos legais, a consolidação da educação básica no país e as atribuições da Educação Física escolar nesse processo, principalmente no ensino médio. Ao longo do século XX, a educação básica se consolidou no Brasil, e a Educação Física escolar se tornou um componente curricular obrigatório, tendo seu papel bem definido pela legislação pertinente. Nas primeiras décadas do século XXI, sua obrigatoriedade curricular passou a ser questionada, especialmente no novo ensino médio, dados os próprios problemas dessa etapa crucial da educação básica, que acaba de passar por uma reforma estrutural e curricular. Conclui-se que as atribuições da Educação Física escolar estão vinculadas ao contexto no qual essas atribuições são forjadas.

Palavras-chave: Educação Física Escolar. Ensino Médio. Reforma.

1 Doutoranda em Ciências Sociais. Universidade Federal de Juiz de Fora (UFJF). Juiz de Fora/Minas Gerais, Brasil. E-mail: vadecastro@hotmail.com

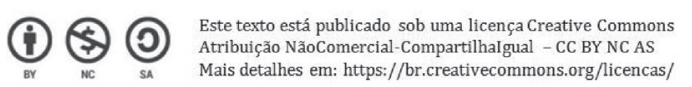




\title{
THE ATTRIBUTIONS OF SCHOOL PHYSICAL EDUCATION: a special focus on High School
}

\begin{abstract}
This paper is a brief reflection about the attributions of school physical education through the 20th and beginning of the 21st centuries, with a special focus on high school. The main objective is to analyze critically, based on legal documentation, the consolidation of basic education in Brazil and the attributions of physical education in said process. It was along the 20th century that basic education consolidated in Brazil and physical education became a mandatory curricular component, with a role well defined by legislation. In the first decades of the 21st century the mandatory aspect began to be questioned, especially in the new high school, given the problems afflicting that stage of basic education that underwent a curricular and structural reform. The conclusion states that the attributions of physical education are bounded to the context in which they are forged.
\end{abstract}

Keywords: School Physical Education. High School. Reform.

\section{LAS ATRIBUCIONES DE LA EDUCACIÓN FÍSICA ESCOLAR: una mirada especial al Enseño Medio}

\section{RESUMEN}

Este trabajo es una pequeña reflexión acerca de las atribuciones de la educación física a través del siglo XX e comenzó del XXI, con una mirada especial en el enseño medio. El objetivo central es analizar críticamente, con base en documentos legales, la consolidación de la educación básica en Brasil y las atribuciones de la educación física en este proceso. Fue al largo del siglo XX que la educación básica se consolidó en Brasil y la educación física quedó como un componente curricular obligatorio, con un papel bien definido por la legislación. En las primeras décadas del siglo XXI el aspecto obligatorio de la disciplina empezó a ser cuestionado, especialmente en el enseño medio, frente a los problemas de esta etapa de la educación básica, objeto de una reciente reforma curricular y estructural. Las conclusiones apuntan que las atribuciones la educación física están directamente conectadas al contexto en que fueran criadas.

Palabras clave: Educación Física Escolar. Enseño Medio. Reforma. 


\section{INTRODUÇÃO}

Para refletir sobre as atribuições da Educação Física escolar, isto é, sobre suas competências, responsabilidades, legitimidades, especialmente no ensino médio, é importante ter em mente o próprio processo de consolidação da educação básica no país e, nesse processo, as atribuições da Educação Física escolar na educação básica como um todo e no ensino médio em particular. Assim, será possível compreender com maior clareza as atribuições dessa disciplina tão importante, que se legitimou como componente curricular obrigatório em todas as etapas da educação básica ao longo do século XX, mas que, nas primeiras décadas do século XXI, passou a ter sua obrigatoriedade curricular questionada, principalmente no novo ensino médio. Diante disso, na primeira sessão desse artigo é realizada uma breve revisão, com base em documentos legais, sobre a consolidação da educação básica no país e as atribuições da Educação Física escolar ao longo do século $X X$, principalmente no ensino médio. Na segunda sessão, revisam-se as atribuições da Educação Física escolar nas primeiras décadas do século XXI, com um enfoque especial no novo ensino médio. Na sequência, apresentam-se as considerações, que nunca são finais.

No Brasil, as preocupações sociais com o direito à educação emergiram tarde. Com um modelo político, social e econômico rural, centrado na mão de obra escrava, as preocupações do Estado com a educação pública emergiram somente no início do século $X X$. Em meados do século XX, com a transição estrutural de uma sociedade agrária para uma sociedade urbana do tipo capitalista, a nova lógica social conferiu à escolarização um papel cada vez mais importante, sendo consolidado um sistema público de educação básica, no qual a Educação Física tornou-se um componente curricular obrigatório. Ao final do século XX, uma das características mais notáveis do sistema educacional brasileiro foi a sua rápida expansão, em todos os níveis, em decorrência de um conjunto de fatores políticos, econômicos e sociais. Nesse período, o número de matrículas no sistema nacional de ensino aumentou substancialmente em todos os níveis. A educação infantil cresceu mais de três vezes. O ensino fundamental quase duplicou de tamanho, sendo praticamente universalizado. O ensino médio passou de mais de um milhão de alunos inscritos, na década de 1970, para aproximadamente sete milhões ao final dos anos 1990. O número de matrículas no ensino superior cresceu quase cinco vezes, a despeito das desigualdades (SILVA, 2003).

Nesse processo, a qualidade da educação se tornou um grande dilema da sociedade brasileira: há uma elevada desigualdade de desempenho educacional entre os estudantes, e boa parcela das crianças e jovens não possuem o nível mínimo de conhecimentos para se inserir em condições mais favoráveis na economia capitalista. A qualidade da educação exerce mais influência no crescimento econômico do país do que as medidas de quantidade, embora as medidas de quantidade como taxas de matrícula e fluxo também sejam importantes. Assim, atualmente, um dos grandes desafios das políticas educacionais é complementar o acesso à escola com políticas sociais que assegurem um nível elevado de 
qualidade da educação, garantindo não somente o acesso ao conhecimento, mas também a infraestrutura necessária à permanência escolar e a aprendizagem de todos os alunos (VELOSO, 2012).

No início do século XXI, muitos dos desafios da educação básica referem-se ao ensino médio. Dentre esses desafios, a universalização do ensino médio, com qualidade e equidade, a correção do fluxo e dos baixos índices de aprendizagem, a promoção de uma educação integral, bem como a adequação do currículo à realidade, ao mercado de trabalho, aos interesses dos jovens e da sociedade brasileira contemporânea, representam grandes desafios às políticas públicas educacionais. Krawczyk (2011) enfatiza que o ensino médio brasileiro é o nível de ensino que provoca os debates mais polêmicos, seja pelos persistentes problemas de acesso e permanência, seja pela qualidade da educação oferecida, ou pela discussão sobre a sua identidade. Fala-se de perda de identidade, quando, na verdade, o ensino médio nunca teve uma identidade muito clara para além de seu papel propedêutico (CASTRO; TAVARES JÚNIOR, 2016). Diante de tantos dilemas que assolam a educação básica, principalmente o ensino médio, esse artigo busca refletir sobre as atribuições da Educação Física escolar, especialmente nessa etapa crucial da escolarização.

\section{A CONSOLIDAÇÃO DA EDUCAÇÃO BÁSICA NO BRASIL E AS ATRIBUIÇÕES DA EDUCAÇÃO FÍSICA ESCOLAR AO LONGO DO SÉCULO XX}

No Brasil, foi somente no início do século XX que a educação pública se consolidou como uma das prioridades nacionais. Nesse período, uma série de debates, reformas e medidas de longo alcance nacional visavam um projeto educacional sólido para o país. Em 1932, por exemplo, foi publicado o Manifesto dos Pioneiros da Educação Nova, no qual membros da elite intelectual, por várias razões, defendiam a escola pública, gratuita, laica e obrigatória. Esse movimento também evidenciou a importância da Educação Física no desenvolvimento integral do ser humano. Nesse contexto, a Constituição Federal de 1934 declarou a educação pública um direito de todos. A Constituição Federal de 1937, por sua vez, normatizou a educação pública, traçando diretrizes para a formação intelectual, moral e física da infância e da juventude, visando prepará-la para a vida em sociedade, o mundo do trabalho e a defesa da nação. A Educação Física foi instituída como uma prática escolar obrigatória em âmbito federal, em todas as escolas primárias, secundárias e normais.

Nesse período, o governo de Getúlio Vargas (1930 - 1945), que tinha como proposta fortalecer o nacionalismo e a indústria de base, visava à implantação de um sistema público de educação que suprisse esses objetivos. Assim, a Educação Física escolar tornou-se um interessante canal de propagação das ideologias da época, sendo utilizada como estratégia na difusão e organização de práticas que tinham como modelo o corpo perfeito, forte, saudável e equilibrado organicamente, pronto para o mundo do trabalho. Nesse contexto, foram incentivadas a educação eugênica e higienista (SILVA; MOREIRA, 2009). As ideologias eugênicas e higienistas, que tinham como proposta a pureza racial e a saúde, foram amplamente adotadas pela sociedade brasileira, vigorando entre o final 
do século XIX e início do século XX, estando presentes na base da formulação de políticas públicas que contribuíram, efetivamente, para o aprofundamento das desigualdades raciais no país (THEODORO, 2008).

Na Constituição Federal de 1946, a educação primária permaneceu proclamada como um direto de todos e assegurada sua gratuidade. Entre os anos de 1950 e as duas décadas seguintes, o país se desenvolveu e se industrializou mais rapidamente, porém, mesmo com a gradual expansão do sistema de ensino, apenas 50\% a 70\% das crianças em idade escolar estavam matriculadas no ensino primário. A situação do ensino secundário era ainda pior, pois apenas $10 \%$ a $20 \%$ dos jovens em idade escolar estavam matriculados nesse nível de ensino (RIBEIRO, 2003).

Nesse período, a vinculação entre educação, produtividade e crescimento econômico ganhou destaque internacional, com a divulgação das teorias do capital humano. Para essas teorias, os indivíduos deveriam competir pelas oportunidades no mercado de trabalho a partir de seu grau de instrução, defendendo-se que, por meio de investimentos pessoais em educação, esforço, talento e mérito, os indivíduos conseguiriam melhorar sua situação social e angariar oportunidades, sendo os únicos responsáveis por suas conquistas e fracassos sociais - a falácia da meritocracia. Nesse contexto, marcado pelo governo de Juscelino Kubitschek (1956 - 1960), a euforia desenvolvimentista se sobressaiu, e a educação entrou para o Plano de Metas com o objetivo de formar mão de obra qualificada para a implantação e ampliação das indústrias de base (SAVIANI, 2008).

Na década de 1960, o sistema público de ensino foi reorganizado em torno do novo contexto político, social e econômico do país. Em 20 de dezembro de 1961, foi promulgada a primeira Lei de Diretrizes e Bases da Educação Nacional, Lei $n^{\circ} 4.024$, que instituiu o ensino primário com quatro anos de duração, obrigatório para crianças a partir dos 07 anos de idade, bem como a educação de nível médio, em prosseguimento à educação primária, destinada à formação dos adolescentes. O ensino médio passou a ser organizado em dois ciclos - ginasial e colegial - abrangendo os cursos secundários, técnicos e de formação de professores para o ensino primário e pré-primário. Nesse contexto, a prática da Educação Física no ensino primário e médio tornou-se obrigatória até a idade de 18 anos. Uma das principais atribuições da Educação Física escolar passou a ser a iniciação ao desporto. A influência do esporte se sobressaiu no sistema educacional enquanto objetivo e conteúdo da Educação Física escolar (DARIDO, 2003).

Com o Golpe Militar (1964 - 1985), o sistema público de educação básica foi novamente reorganizado. Em 11 de agosto de 1971, foi promulgada a segunda Lei de Diretrizes e Bases da Educação Nacional, Lei no 5.692, que tornou compulsório o ensino de $1^{\circ}$ grau, com oito anos de duração, para crianças de 07 a 14 anos de idade, estabelecendo também as normas para o $2^{\circ}$ grau (ensino médio). Passou a ser obrigatória a inclusão de Educação Moral e Cívica, Educação Física, Educação Artística e Programas de Saúde nos currículos dos estabelecimentos de ${ }^{\circ}$ e $2^{\circ}$ graus. Nesse contexto, o Decreto $\mathrm{n}^{\circ} 69.450$, de $1^{\circ}$ de novembro de 1971, vigente até o ano de 1996, atribuiu à Educação Física escolar a responsabilidade de desenvolver e aprimorar as forças físicas, valores morais e cívicos, habilidades psíquicas e sociais. No ensino médio, a Educação Física escolar deveria 
contribuir para o desenvolvimento e aprimoramento dessas potencialidades, possibilitando uma perfeita sociabilidade, a conservação da saúde, o fortalecimento da vontade e o estímulo à liderança.

Na década de 1980, esse modelo passou a ser cada vez mais contestado. Nesse contexto, diversas abordagens teóricas se destacaram, visando uma Educação Física articuladora das dimensões humanas. Tais abordagens têm em comum a tentativa de romper com o modelo tradicional, tecnicista e esportivista. Dentre essas abordagens, podemos destacar a Humanista, Fenomenológica, Psicomotricidade, Cultural, Desenvolvimentista, Interacional-Construtivista, Crítico-Superadora, Sistêmica, Crítico-Emancipatória e a abordagem dos Parâmetros Curriculares Nacionais (DARIDO, 2012). Ao final dos anos 1980, houve o fim da Ditadura Militar, e o país passou por um processo de democratização. Nesse contexto, foi promulgada a Constituição Federal de 1988, destinada a assegurar o exercício dos direitos individuais e sociais, tal como a educação. Instaura-se no país um novo contexto político democrático.

Na década de 1990, durante o governo de Fernando Henrique Cardoso (1995 - 2003), foi promulgada a terceira Lei de Diretrizes e Bases da Educação Nacional, Lei no 9.394 de 20 de dezembro de 1996, que estabeleceu padrões para o ensino compulsório, currículo escolar, qualificação dos professores, expansão de matrículas, promoção de alunos, criação de estatísticas educacionais e avaliação dos estudantes. As finalidades do ensino médio passam a ser a consolidação e o aprofundamento dos conhecimentos adquiridos no ensino fundamental, possibilitando o prosseguimento dos estudos, a preparação para o trabalho e a cidadania, o aprimoramento como pessoa humana, incluindo a formação ética e o desenvolvimento da autonomia intelectual e do pensamento crítico. A Educação Física foi integrada à proposta pedagógica da escola como um componente curricular obrigatório da educação básica, ajustando-se às faixas etárias e às necessidades da população escolar, sendo facultativa nos cursos noturnos.

Nesse período, os Parâmetros Curriculares Nacionais passaram a direcionar as atribuições da Educação Física escolar segundo a cultura corporal de movimento. O documento que constitui os Parâmetros Curriculares Nacionais foi organizado pelo Ministério da Educação ao final dos anos 1990 e início da década seguinte para nortear a educação básica em todo o país, visando garantir a todas as crianças e adolescentes o acesso a um conjunto comum de conhecimentos socialmente elaborados, considerados indispensáveis para o exercício da cidadania (BRASIL, 1998). De acordo com os Parâmetros Curriculares Nacionais, dentre as atribuições da Educação Física escolar encontra-se a transmissão de um vasto patrimônio cultural da humanidade, ligado aos jogos, esportes, lutas, danças e ginásticas, dentre outras práticas que constituem a cultura corporal (BRASIL, 1998). Assim, tornou-se dever da Educação Física escolar proporcionar a vivência da cultura corporal, com enfoque nas dimensões culturais, simbólicas, inclusivas, críticas, de lazer e de saúde (DARIDO, 2012).

Segundo Soares et al. (1992), no âmbito da Educação Física escolar, a cultura corporal é uma reflexão pedagógica acerca das representações de mundo construídas pelos homens no decorrer da história, exteriorizadas por meio da expressão corporal. A cultura 
corporal é o resultado de práticas corporais historicamente produzidas e acumuladas pela humanidade, desde jogos, lutas, ginásticas, danças, esportes, dentre outras. Deve ser transmitida aos alunos nas aulas de Educação Física escolar, contribuindo para a afirmação de valores e identidades. A afirmação de valores e identidades é condição objetiva para a construção da consciência, para o engajamento deliberado na luta pela transformação da sociedade e para a conquista da hegemonia popular. Desta forma, os conteúdos da cultura corporal deveriam ser vivenciados nas aulas de Educação Física, possibilitando aos alunos a compreensão da sociedade, visando à superação do senso comum, permitindo a constatação, interpretação, compreensão, explicação e crítica acerca da cultura corporal (SOARES et al., 1992).

Assim, a Educação Física escolar passa a ser entendida como uma área de conhecimento da cultura corporal de movimento, cuja atribuição é introduzir os alunos nesta cultura, visando formar cidadãos críticos, capazes de reproduzir e transformar a cultura corporal. A Educação Física escolar tem o dever de localizar nas modalidades da cultura corporal seus benefícios e possibilidades de comunicação, expressão de sentimentos e emoções, lazer e saúde. Deve proporcionar oportunidades a todos os alunos para desenvolverem suas potencialidades de forma democrática, visando ao seu aprimoramento como ser humano (BRASIL, 1998). Os Parâmetros Curriculares Nacionais passam a propor uma Educação Física escolar voltada a todos os alunos, sem discriminação, bem como o relacionamento das atividades da Educação Física com os grandes problemas da sociedade brasileira, sem perder de vista o seu papel de integrar o cidadão na esfera da cultura corporal (DARIDO et al., 2001).

Nota-se que, ao longo do século XX, a Educação Física escolar se consolidou enquanto um componente curricular obrigatório em todas as etapas da educação básica, com diversas atribuições, de acordo com os contextos histórico, social, político, econômico e cultural da sociedade. Nesse processo, as atribuições da Educação Física escolar estiveram relacionadas à inculcação de valores nacionais, à preparação do aluno para o mundo do trabalho, à aptidão física e esportiva, à promoção da saúde e lazer, à iniciação a cultura corporal de movimento, dentre outros. Na primeira década do século XXI, a obrigatoriedade da Educação Física escolar, principalmente no novo ensino médio, passa a ser questionada, bem como suas atribuições. Todavia, o ensino médio, por si só, já é a etapa da educação básica mais conturbada. Dentre os muitos problemas que assolam essa etapa, está a própria composição da grade curricular. Assim, passa-se a questionar não somente a obrigatoriedade da Educação Física, mas também de outros componentes curriculares do ensino médio. Diante disso, o espaço dessas disciplinas, assim como os próprios rumos dessa etapa crucial da educação básica, permanece em aberto neste início de século.

\section{AS ATRIBUIÇÕES DA EDUCAÇÃO FíSICA ESCOLAR NAS PRIMEIRAS DÉCADAS DO SÉCULO XXI: UM ENFOQUE ESPECIAL NO NOVO ENSINO MÉDIO}

A partir dos anos 2000, além dos Parâmetros Curriculares Nacionais, outros documentos e resoluções passaram a nortear o currículo da educação básica e as atribuições 
da Educação Física escolar. Um exemplo são as Diretrizes Curriculares Nacionais Gerais para a Educação Básica, Resolução no 4, de 13 de julho de 2010, do Conselho Nacional de Educação, documento cujo objetivo visa sistematizar os princípios e diretrizes da educação básica contidos na Constituição Federal de 1988 e na Lei de Diretrizes e Bases da Educação Nacional de 1996. Nesse documento, a principal atribuição da Educação Física escolar é desenvolver habilidades indispensáveis ao exercício da cidadania (BRASIL, 2013). Outro exemplo é a Base Nacional Comum Curricular, que embora não tenha uma versão definitiva publicada, compõe um conjunto de orientações curriculares para as escolas das redes públicas e privadas de todo o Brasil. Trata-se de um documento organizado pelo Ministério da Educação, que visa trazer os conhecimentos e competências que devem ser aprendidas pelas crianças e jovens em cada etapa da educação básica (BRASIL, 2016).

$\mathrm{Na}$ Base Nacional Comum Curricular, a Educação Física foi integrada à área de Linguagens, que reúne as disciplinas Arte, Língua Portuguesa, Língua Estrangeira Moderna e Educação Física. Essa área de conhecimento abrange a linguagem verbal, musical, visual e corporal, visando esses recursos expressivos na participação da vida social. O termo abrange também diferentes formas de experiências estéticas, sensoriais, sensíveis, corporais, sonoras, dentre outras. Dentro da área de Linguagens, a atribuição da Educação Física escolar é tratar das práticas que constituem a cultura corporal de movimento, considerando o acesso, a pluralidade, as transformações, o combate a preconceitos, bem como a interface das práticas corporais com a saúde, o lazer, a estética, dentre outros (BRASIL, 2016). No entanto, o texto da Base Nacional Comum Curricular está em discussão desde 2015, já está na terceira versão e, até o momento, não gerou e, provavelmente, não irá gerar consenso entre os educadores.

Nas primeiras décadas do século XXI, além das polêmicas em torno da redação da Base Nacional Comum Curricular, tem-se a atual reforma do ensino médio, considerada a maior alteração feita nesta etapa da educação básica desde a promulgação da Lei de Diretrizes e Bases da Educação Nacional, em 1996. A reforma do ensino médio foi instituída pela Medida Provisória n ${ }^{\circ} 746$ de 22 de setembro de 2016, sendo sancionada pelo presidente interino em 16 de fevereiro de 2017, sem consenso entre governo, educadores e sociedade civil. Trata-se de uma mudança estrutural nesse nível de ensino, que propõe a flexibilização da grade curricular. Com a reforma, a obrigatoriedade da Educação Física no novo ensino médio passou a ser questionada.

No novo ensino médio, o aluno pode optar por uma área do conhecimento para aprofundar seus estudos, visto que passa a ser composto por um conjunto de disciplinas comuns e obrigatórias a todas as escolas (como Português, Matemática e Língua Inglesa, que serão obrigatórias nos três anos do ensino médio); e outro conjunto de disciplinas flexíveis, segmentadas segundo cinco áreas do conhecimento (Linguagens, Matemática, Ciências da Natureza, Ciências Humanas e Formação Técnica), de acordo com a Base Nacional Comum Curricular. Assim, a Educação Física integra a área de Linguagens, que funcionará como optativa, isto é, tanto as escolas podem ou não oferecer, visto que ficam obrigadas a oferecerem no mínimo uma das cinco áreas, quanto o aluno pode escolher cursar ou não, visto que poderá escolher somente uma das cinco áreas para complementar seu currículo do ensino médio. 
No entanto, dentre os problemas que a reforma do ensino médio, tal como foi instituída, pode acarretar está o acesso desigual às áreas de conhecimento, uma vez que a reforma prevê que as escolas ofereçam, no mínimo, uma das cinco áreas. Assim, nada garante que a área optada pelo aluno será oferecida pela escola mais próxima de sua residência. Desta forma, o aluno terá que se locomover pela cidade em busca de outra escola que ofereça a área de conhecimento de seu interesse, ou então será fadado a permanecer na escola mais próxima de sua residência, cursando a área que essa escola tenha a oferecer, independente de seu interesse. Problema semelhante ocorrerá em pequenas cidades com poucas escolas. Tal mudança também gera uma desigualdade de acesso às áreas do conhecimento ao observar as escolas públicas e particulares, que provavelmente irão ofertar mais áreas para garantir sua clientela.

A reforma do ensino médio é um projeto polêmico desde a sua criação. É proposto um percurso segmentado, em que o estudante pode seguir os estudos em direção a uma área específica do conhecimento ou formação técnica e profissional, desconsiderando sua formação como um todo. A reforma ainda prevê o ensino médio em tempo integral e permite que os sistemas de ensino autorizem profissionais com "notório saber" a ministrarem aulas nas disciplinas dos cursos técnicos e profissionalizantes. O "notório saber", algo que não está muito bem definido, aponta para a desvalorização da profissão docente. O texto da Medida Provisória $n^{\circ}$ 746/2016, que institui a reforma do ensino médio, não é claro em muitos outros aspectos.

Não existe consenso sobre a reforma do ensino médio, especialmente pela forma como foi conduzida e instituída pelo presidente interino. Com o processo de impeachment da presidente Dilma Rousseff (2014 - 2016), houve uma grave ruptura democrática no país, principalmente pelo modo como o processo se sucedeu, causando um grande mal estar na sociedade e um cenário de instabilidade política, econômica e social. Diversos segmentos da sociedade se opuseram a esse processo, considerado um golpe, por se tratar de um risco à democracia e aos direitos políticos e sociais. Nesse contexto, o vice-presidente Michel Temer (2016) assumiu interinamente a presidência da República, buscando desconstruir as políticas sociais, econômicas e culturais do governo Dilma, em uma clara ruptura, comprometendo ganhos sociais recentes e conquistas ratificadas pela Constituição Federal de 1988. O governo interino trocou ministros e secretários, fundiu e eliminou ministérios, articulou a reforma do ensino médio e outras reformas que vão à contramão do governo Dilma e das conquistas sociais.

Por esse e por outros motivos, não há consenso sobre a reforma do ensino médio. De um lado, argumenta-se que o ensino médio possui um extenso currículo, composto de disciplinas acadêmicas obrigatórias, mesmo para os jovens que escolhem uma formação profissional de nível técnico, defendendo-se a necessidade de um currículo mínimo obrigatório e a possibilidade de completá-lo através de disciplinas eletivas, bem como articulá-lo à educação profissional, flexibilizando o currículo. De outro lado, critica-se a ausência de interlocução entre o Ministério da Educação, o Congresso Nacional, a sociedade e, principalmente, a juventude, argumentando-se que a reforma do ensino médio culmina em uma escola dual, que prepara para a universidade ou para o mercado de trabalho, mas 
que não resolve problemas mais complexos e estruturais do sistema de ensino (CASTRO; TAVARES JÚNIOR, 2016).

Diante disso, nas primeiras décadas do século XXI, a Educação Física escolar passa por uma crise de legitimidade, principalmente no que tange à sua obrigatoriedade curricular no novo ensino médio. Contudo, a crise de legitimidade recai sobre o próprio ensino médio. Não há clareza sobre os objetivos e finalidades dessa etapa crucial da educação básica, que por si só já é tão problemática. Com a reforma, tal como foi instituída, os problemas tendem a piorar. Passa-se a questionar não somente a obrigatoriedade da Educação Física escolar, mas também de outros componentes curriculares do ensino médio, principalmente referentes à área de Humanidades, indispensáveis na formação integral do aluno. É necessário definir e organizar com clareza e consenso essa etapa final da educação básica, cujos horizontes nesse momento estão nublados. Nesse contexto delicado, de crise política, econômica e social, é imprescindível argumentos críticos e inovadores para reorganizar o ensino médio e legitimar a importância e as atribuições de seus componentes curriculares na formação integral dos jovens, considerando as necessidades da juventude, a singularidade dessa faixa etária e as experiências individuais. Para tanto, é preciso dialogar, reivindicar, resistir e garantir o direito ao acesso não somente à Educação Física, mas também a outras áreas de conhecimento.

\section{CONSIDERAÇÕES}

Percebe-se que as atribuições da Educação Física escolar estão intrinsecamente vinculadas ao contexto histórico, político, social, econômico e cultural no qual essas atribuições são forjadas. Assim, em cada época, de acordo com a conjuntura, distintos argumentos legitimam as atribuições e a própria obrigatoriedade da Educação Física escolar. Uma vez que esses argumentos estão vinculados ao contexto da sociedade, os argumentos que legitimam a Educação Física escolar em um determinado momento podem ser considerados inadequados em outro momento. Desta forma, os argumentos são sempre repaginados de acordo com os interesses predominantes no contexto da sociedade. Assim, é importante considerar as particularidades históricas, políticas, sociais, econômicas e culturais para entendermos os interesses, as disputas e o próprio desenrolar não somente da Educação Física escolar, mas da educação básica como um todo, principalmente, sua conjuntura atual.

\section{REFERÊNCIAS}

AZEVEDO, F. et al. Manifestos dos pioneiros da Educação Nova (1932) e dos educadores (1959). Recife: Editora Massangana, 2010. Disponível em http://www.dominiopublico. gov.br/download/texto/me4707.pdf Acesso 30/03/2017.

BRASIL. Base Nacional Comum Curricular. Segunda Versão Revista. Brasília, DF: Ministério da Educação, 2016. Disponível em http://basenacionalcomum.mec.gov.br/documentos/ bncc-2versao.revista.pdf Acesso 30/03/2017. 
BRASIL. Constituição da República dos Estados Unidos do Brasil, de 16 de julho de 1934. Disponível em http://www.planalto.gov.br/ccivil_03/constituicao/constituicao34.htm Acesso 30/03/2017.

BRASIL. Constituição dos Estados Unidos do Brasil, de 10 de novembro de 1937. Disponível em http://www.planalto.gov.br/ccivil_03/constituicao/constituicao37.htm Acesso 30/03/2017.

BRASIL. Constituição dos Estados Unidos do Brasil, de 18 de setembro de 1946. Disponível em http://www.planalto.gov.br/ccivil_03/constituicao/constituicao46.htm Acesso 30/03/2017.

BRASIL. Constituição da República Federativa do Brasil, de 05 de outubro de 1988. Disponível em http://www.planalto.gov.br/ccivil_03/constituicao/constituicao.htm Acesso 30/03/2017.

BRASIL. Decreto $\mathbf{n}^{\mathbf{0}}$ 69.450, de $\mathbf{1}^{\mathbf{0}}$ de novembro de 1971. Regulamenta o artigo 22 da Lei número 4.024, de 20 de dezembro de 1961 e dá outras providências. Disponível em http://www.planalto.gov.br/ccivil_03/decreto/d69450.htm Acesso 30/03/2017.

BRASIL. Diretrizes Curriculares Nacionais Gerais da Educação Básica. Brasília, DF: Ministério da Educação, 2013. Disponível em http://portal.mec.gov.br/docman/julho2013-pdf/13677-diretrizes-educacao-basica-2013-pdf/file Acesso 30/03/2017.

BRASIL. Lei $\mathbf{n}^{\mathbf{0}}$ 4.024, de 20 de dezembro 1961. Estabelece as diretrizes e bases da educação nacional. Disponível em http://www2.camara.leg.br/legin/fed/lei/1960-1969/ lei-4024-20-dezembro-1961-353722-publicacaooriginal-1-pl.html Acesso 20/03/2017 Acesso 30/03/2017.

BRASIL. Lei no 5.692, de 11 de agosto de 1971. Estabelece as diretrizes e bases da educação nacional. Disponível em http://www2.camara.leg.br/legin/fed/lei/1970-1979/lei-569211-agosto-1971-357752-publicacaooriginal-1-pl.html Acesso 30/03/2017.

BRASIL. Lei no 9.394, de 20 de dezembro 1996. Estabelece as diretrizes e bases da educação nacional. Disponível em http://www.planalto.gov.br/ccivil_03/leis/L9394.htm Acesso 20/03/2017 Acesso 30/03/2017.

BRASIL. Medida Provisória $\mathbf{n}^{\mathbf{0}}$ 746, de 22 de setembro de 2016. Institui a reforma do ensino médio e dá outras providências. Diário Oficial da União, Brasília, DF, sexta-feira, 23 de setembro de 2016. Disponível em http://portal.mec.gov.br/index. php? option $=$ com_docman \&view $=$ download \&alias $=48601-\mathrm{mp}-746$-ensino-mediolink-pdf\&category_slug=setembro-2016-pdf\&ltemid=30192 Acesso 30/03/2017.

BRASIL. Parâmetros curriculares nacionais: terceiro e quarto ciclos: Educação Física. Brasília: Ministério da Educação/Secretaria de Ensino Fundamental, 1998. Disponível em http://portal.mec.gov.br/seb/arquivos/pdf/fisica.pdf Acesso 30/03/2017.

BRASIL. Parâmetros curriculares nacionais: ensino médio. Brasília: Ministério da Educação/ Secretaria de Ensino Médio, 1999. Disponível em http://portal.mec.gov.br/setec/ arquivos/pdf/BasesLegais.pdf Acesso 30/03/2017.

CASTRO, G., V.; TAVARES Jr, F. Jovens em Contextos Sociais Desfavoráveis e Sucesso Escolar no Ensino Médio. Educação e Realidade, Porto Alegre, vol. 41, p. 239-258, 2016. DARIDO, S. C. et al. A Educação Física, a formação do cidadão e os parâmetros curriculares 
setembro/2017

nacionais. Revista Paulista de Educação Física, São Carlos, vol. 15, n. 01, p. 17-32, 2001.

DARIDO, S. C. Diferentes Concepções sobre o Papel da Educação Física na Escola.

Cadernos de Formação: Conteúdos e Didática de Educação Física, São Paulo, vol. 01, p. 34-50, 2012.

DARIDO, S. C. Educação Física na escola: questões e reflexões. Rio de Janeiro: Guanabara/ Koogan, 2003.

KRAWCZYK, N. Reflexão sobre alguns desafios do ensino médio no Brasil hoje. Cadernos de Pesquisa, São Paulo, vol. 41, n 144, p. 752-769, set/dez. 2011.

RIBEIRO, Carlos Antonio Costa. Estrutura de classe e mobilidade social no Brasil. Bauru: Edusc, 2007.

SAVIANI, D. O legado educacional do regime militar. Cad. Cedes, Campinas, vol. 28, n. 76, p. 291-312, set./dez. 2008.

SILVA, M. C. P.; MOREIRA, A. J. A cultura corporal nas diretrizes da Lei no 10.639/2003 da Secretaria Municipal de Educação e Cultura de Salvador: propósitos e despropósitos. In: TENÓRIO, R.; LORDÊLO, J. A. C. (Org.). Educação básica: Contribuições da pósgraduação e da pesquisa. Salvador: EDUFBA, 2009.

SILVA, N. V. Expansão Escolar e Estratificação Educacional no Brasil. In HASENBALG, C.; SILVA, N. V. (Org.). Origens e Destinos: Desigualdades Sociais ao Longo da Vida. Rio de Janeiro: Topbooks, 2003.

SOARES, C. L. et al. Coletivo de Autores. Metodologia do Ensino de Educação Física. São Paulo: Cortez, 1992.

THEODORO, M. A Formação do Mercado de Trabalho e a Questão Racial no Brasil. In: THEODORO, M.; JACCOUD, L.; OSÓRIO, R.; SOARES, S (Org.). As políticas públicas e a desigualdade racial no Brasil: 120 anos após a abolição. Brasília: IPEA, 2008.

VELOSO, F. A. Qualidade da Educação, Inclusão Econômico-Social e Crescimento. In: XXIV Fórum Nacional Rumo ao Brasil Desenvolvido. Anais... Rio de Janeiro: INAE, 2012. 